\title{
Precursor Ion Scanning for Detection and Structural Characterization of Heterogeneous Glycopeptide Mixtures
}

\author{
Mark A. Ritchie and Andrew C. Gill \\ Institute for Animal Health, Compton, Berkshire, United Kingdom \\ Michael J. Deery and Kathryn Lilley \\ Department of Biochemistry, Cambridge Centre for Proteomics, University of Cambridge, Cambridge, United \\ Kingdom
}

\begin{abstract}
The structure of N-linked glycans is determined by a complex, anabolic, intracellular pathway but the exact role of individual glycans is not always clear. Characterization of carbohydrates attached to glycoproteins is essential to aid understanding of this complex area of biology. Specific mass spectral detection of glycopeptides from protein digests may be achieved by on-line HPLC-MS, with selected ion monitoring (SIM) for diagnostic product ions generated by cone voltage fragmentation, or by precursor ion scanning for terminal saccharide product ions, which can yield the same information more rapidly. When glycosylation is heterogeneous, however, these approaches can result in spectra that are complex and poorly resolved. We have developed methodology, based around precursor ion scanning for ions of high $\mathrm{m} / \mathrm{z}$, that allows site specific detection and structural characterization of glycans at high sensitivity and resolution. These methods have been developed using the standard glycoprotein, fetuin, and subsequently applied to the analysis of the N-linked glycans attached to the scrapieassociated prion protein, $\mathrm{PrP}^{\mathrm{Sc}}$. These glycans are highly heterogeneous and over 30 structures have been identified and characterized site specifically. Product ion spectra have been obtained on many glycopeptides confirming structure assignments. The glycans are highly fucosylated and carry Lewis $X$ or sialyl Lewis $X$ epitopes and the structures are in-line with previous results. [Abbreviations: Hex-Hexose, $\mathrm{C}_{6} \mathrm{H}_{12} \mathrm{O}_{6}$ carbohydrates, including mannnose and galactose; HexNAc- $\mathrm{N}$-acetylhexosamine, $\mathrm{C}_{8} \mathrm{H}_{15} \mathrm{NO}_{6}$ carbohydrates, including N-acetylglucosamine and N-acetylgalactosamine; GlcNAc-N-acetylglucosamine; GalNAc-N-acetylgalactosamine; Fuc-Fucose; NeuAC - N-acetylneuraminic acid or sialic acid; TSE-Transmissible Spongiform Encephalopathy.] (J Am Soc Mass Spectrom 2002, 13, 1065-1077) (C) 2002 American Society for Mass Spectrometry
\end{abstract}

$\mathrm{O}$ ne of the major challenges for mass spectrometry in the post-genomic era is the qualitative and quantitative characterization of post-translational modifications of proteins. A plethora of biologically relevant modifications exists, characterized by small changes in mass, for example deamidation of asparagine or glutamine residues or disulphide bond formation, to larger changes in mass, for example phosphorylation of serine, threonine, or tyrosine residues or N-glycosylation of specific asparagine residues. Post-translational modifications are of vital importance since they frequently determine, or are involved in, protein structure, function, ligand binding, proteinprotein interactions or regulation of function. Thus, the detection and characterization of a protein's post-trans-

Published online July 25, 2002

Address reprint requests to Dr. A. C. Gill, Institute for Animal Health, Compton, Berkshire RG20 7NN, UK. E-mail: andrew.gill@bbsrc.ac.uk lational modifications could be considered at least as important as the confirmation of identity of the protein itself.

Amongst cell-surface proteins, the most ubiquitous modification is glycosylation. Typically, carbohydrates can be linked to proteins via the oxygen atoms of serine or threonine side chains (O-linked glycosylation) or to the nitrogen atom of asparagine side chains (N-linked glycosylation). Asparagine residues appearing in the consensus sequence Asn-Xxx-Ser/Thr may be modified co-translationally in the endoplasmic reticulum (ER) by the addition of large "core" oligosaccharides. These structures are then trimmed and modified by a variety of enzymes as the protein is transported through the ER and the golgi, potentially resulting in a highly heterogeneous population of carbohydrates [1, 2]. Such carbohydrates have been implicated in a wide range of functions, from aiding protein folding [1] to mediating cell-cell signalling [3], but a detailed understanding of 


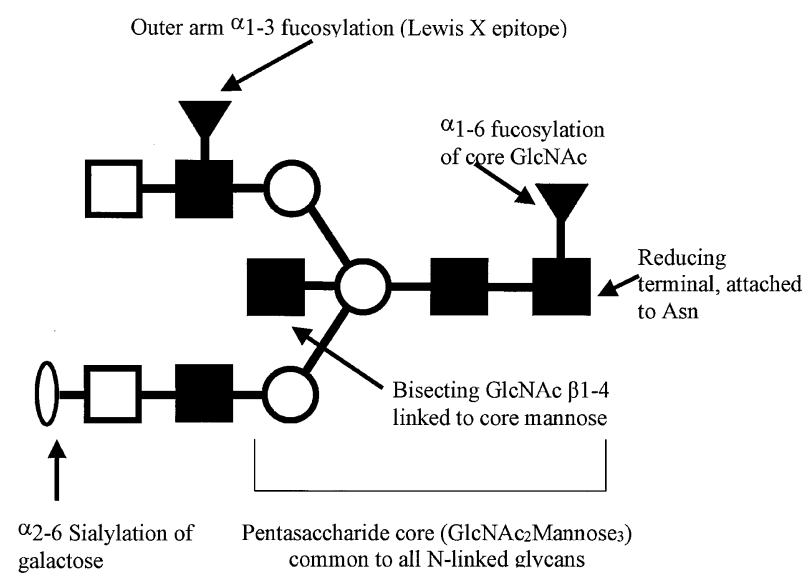

Figure 1. Structural features of a complex type Asn-linked glycan typical to neural tissue. Key to structures: Filled square GlcNAc, open square galactose, open circle mannose, zero NeuAc, filled inverted triangle fucose.

the function of individual carbohydrates remains elusive. It is therefore vital to characterize all carbohydrates attached to a glycoprotein to aid understanding of the role of these structures in normal cell biology. It is also important to detect changes in glycan structure during pathogenesis of various diseases since perturbations in the biochemistry of the cell can have profound effects on the products of the glycosylation pathway. In a number of disorders, glycosylation on certain proteins is specifically altered and is indicative of that disease [4-9].

Under electrospray ionization conditions, the use of high cone voltages, to promote "in-source" fragmentation of ions, in conjunction with selected ion monitoring (SIM) experiments, allows the specific detection of glycopeptides from proteolytic digests separated by on-line HPLC [10]. Frequently used diagnostic fragment ions for SIM experiments are $m / z 204\left(\mathrm{HexNAc}^{+}\right)$, $274\left(\left[\mathrm{NeuAc}-\mathrm{H}_{2} \mathrm{O}\right]^{+}\right), 292\left(\mathrm{NeuAc}^{+}\right)$, or $366(\mathrm{Hex}-\mathrm{Hex}-$ $\left.\mathrm{NAc}^{+}\right)$. When unseparated peptide or glycopeptide mixtures are analyzed by electrospray or nanospray MS, precursor ion scans for one or more of these daughter ions in a tandem mass spectrometer specifically identifies glycopeptides [11, 12]. Precursor ion scans of heterogeneous glycopeptide mixtures, however, can yield complex spectra where peaks are often incompletely resolved. The level of complexity increases when more than one site of N-linked glycosylation is present within a protein.

Since carbohydrates are typically composed of only a limited number of types of monosaccharide, and all N-linked carbohydrates share the same core structure of two GlcNAcs attached to trimannose (Figure 1), an accurate mass measurement can often give a good indication of carbohydrate composition. In order to characterize fully the structure of the carbohydrates, the use of MS/MS experiments or exo-glycosidase digestion is considered essential [10,13,14]. We present an alternative strategy for highly sensitive and rapid analysis of heterogeneous glycopeptide mixtures based on precursor ion scanning for high $\mathrm{m} / \mathrm{z}$ ions, which yields not only high resolution spectra but also provides structural characterization of the carbohydrate moieties. The method also allows carbohydrates to be characterized site specifically, even if a mixture of glycosylation sites is present in the same mixture. Our strategy has been developed using the standard glycopeptide fetuin, and has then been applied to the analysis of the $\mathrm{N}$-linked glycans of hamster $\mathrm{PrP}^{\mathrm{Sc}}$, the scrapie-associated prion protein, which carries up to 60 different glycoforms attached to two different sites [14, 15].

The prion protein is the key protein in the transmissible spongiform encephalopathies (TSEs), a family of diseases including bovine spongiform encephalopathy (BSE) and Creutzfeldt-Jakob disease (CJD), where the protein accumulates in large, insoluble aggregates. Sodium dodecylsulfate polyacrylamide gel electrophoresis (SDS-PAGE) analysis of $\operatorname{PrP}^{\mathrm{Sc}}$ extracted from animal brains suggests that occupancy levels of the two glycosylation sites can vary depending on the strain of TSE. It is not known, however, whether individual glycan structures also differ between strains, or whether relative proportions of each structure are similar. Characterization of the carbohydrates attached to $\mathrm{PrP}^{\mathrm{Sc}}$ is therefore essential to understand fully the role that this protein plays in pathogenesis of these fatal, neurodegenerative diseases. Previous work in this area has focused on the characterization of carbohydrates attached to murine $\operatorname{PrP}^{\mathrm{Sc}}$ from a single TSE strain [14] or on the differences in carbohydrate structures between $\operatorname{PrP}^{\mathrm{Sc}}$ and $\operatorname{PrP}^{\mathrm{C}}$, the normal, cellular isoform [15]. Our novel methodology has been developed to provide a rapid method of mapping carbohydrate structure profiles without lengthy labeling or digestion steps and should enable the identification of any structures specific to individual TSE strains.

\section{Experimental}

\section{Protein Digestion and Purification}

Fetuin from fetal calf serum was obtained from Sigma and was used without further purification. $\operatorname{PrP}^{\mathrm{Sc}}$ was purified from the brains of scrapie-infected hamsters by detergent lysis and differential centrifugation according to the protocol of Hope et al. [16]. Proteins were dissolved in $6 \mathrm{M}$ guanidinium $\mathrm{HCl}$, reduced and alkylated by dithiothreitol and 4-vinyl pyridine respectively before being precipitated by the addition of 20 volumes of ice cold ethanol. Proteins were redissolved in $2 \mathrm{M}$ urea, $100 \mathrm{mM}$ ammonium bicarbonate, $\mathrm{pH} 8.0$, and were digested by the addition of approximately 5\% $(\mathrm{w} / \mathrm{w})$ trypsin (Sigma, Dorset, UK). Tryptic peptides from both proteins were desalted by binding the peptide mixture onto a $\mathrm{C}_{18}$ ZipTip (Millipore, Bedford, MA) and step eluting with $0.1 \%$ (vol/vol) trifluroacetic acid or $0.05 \%$ formic acid in 50:50 acetonitrile:water according to the manufacturers instructions. Where necessary, glycopeptides from the digest mixture were separated 


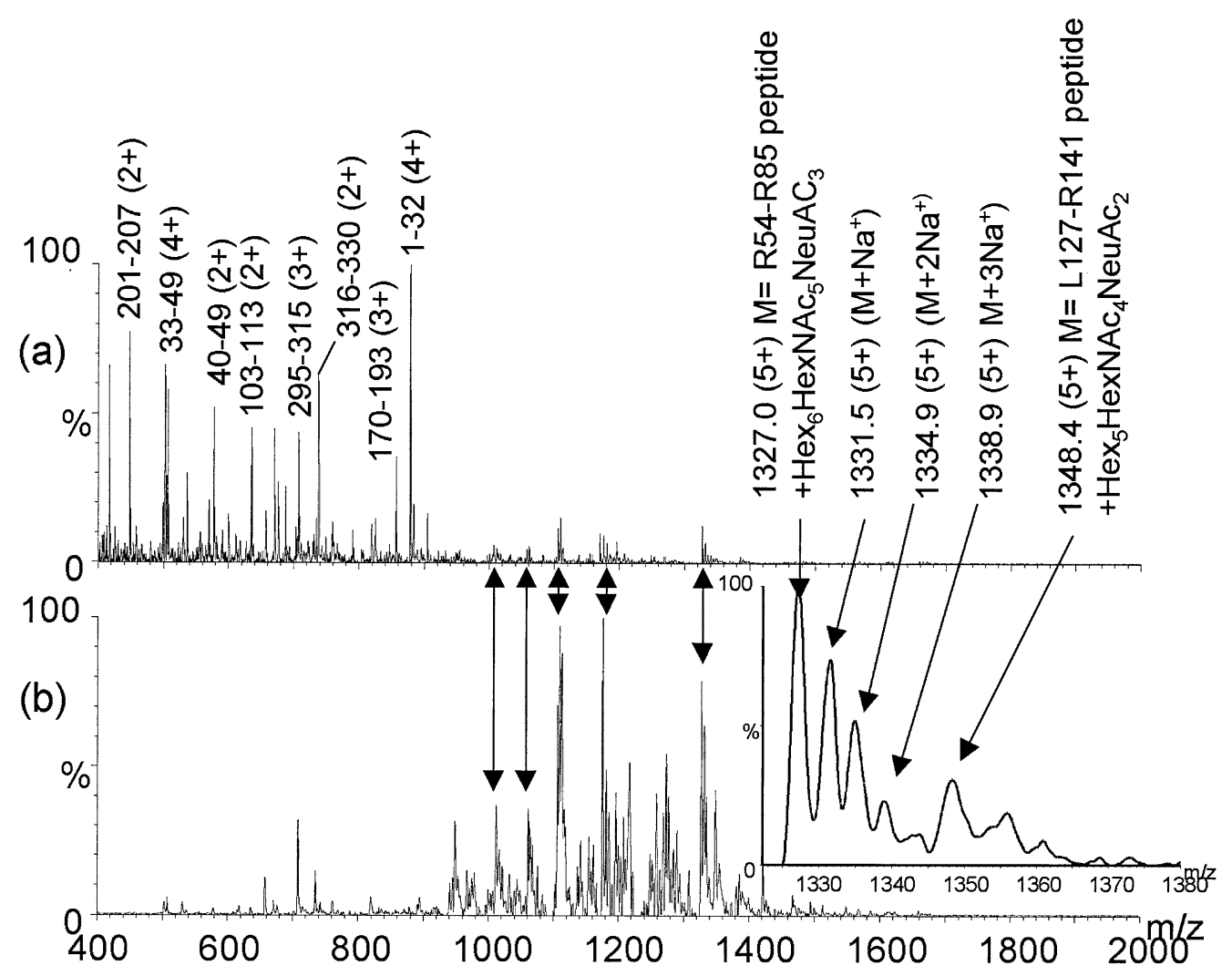

Figure 2. MS of tryptic digest of fetuin. (a) MS1 scan, peptides are labeled with amino acid residue numbers; (b) precursor ion scan for $\mathrm{m} / \mathrm{z} 204$, the immonium ion of HexNAc, indicating ions of glycopeptides from all glycosylation sites. Glycopeptides visible in the MS1 scan are arrowed. (b inset) Magnification of $\mathrm{m} / \mathrm{z} 204$ scan showing sodium adducts on glycopeptide ions.

on a semi-preparative HPLC column $(2.1 \mathrm{~mm}$ i.d., $15 \mathrm{~cm}$ length, $3.5 \mu \mathrm{m}$ bead size, $150 \AA$ pore size, Hichrom, Ltd, Berkshire, UK). The eluent was monitored by passing approximately $1 \%$ of the flow through a Z-view UV flow cell (LC Packings, Amsterdam, The Netherlands), to the mass spectrometer whilst the remaining $99 \%$ was collected in fractions.

\section{Mass Spectrometry}

Mass spectrometry was by use of either a Quattro II tandem quadrupole instrument (Micromass UK Ltd., Manchester, UK) or a hydrid quadrupole-time of flight instrument (Q-ToF, Micromass) both equipped with commercial Z-spray sources. Desalted glycopeptide fractions (peptide concentration estimated to be 5-10 pmole $/ \mu \mathrm{l}$ ) were loaded in $1 \mu \mathrm{l}$ aliquots into borosilicate capillaries that had been pulled (Sutter puller Model 753, Campden Instruments Ltd., Leicestershire, UK) and platinum coated using a sputter coater (Polaron SEM coating unit E5100, Quorum Technologies, East Sussex, UK) in-house or gold-coated borosilicate capillaries (Micromass). Approximately $1 \mathrm{kV}$ was applied to the spraying capillary resulting in spraying flow rates of around $20 \mathrm{nl} / \mathrm{min}$. The Quattro II was used for MS1 scans $(m / z 300-2200,5 \mathrm{~s}$ per scan, at least 10 scans summed) for precursor ion scans $(m / z$ 400-2200, $20 \mathrm{~s}$ per scan, at least 100 scans summed) and for some product ion scanning $(\mathrm{m} / \mathrm{z} 50-2300,20 \mathrm{~s}$ per scan, at least 50 scans summed). Typical collisional activation conditions were around 3.5 mbar of Argon and a collision energy of 25-40 V. The Q-TOF instrument was used for product ion scans of low abundance glycopeptides under similar fragmentation conditions.

For monitoring $\mathrm{PrP}^{\mathrm{Sc}}$ tryptic peptide HPLC separation, a continuous flow nanospray source was used on the Quattro II instrument. $20 \mu \mathrm{m}$ fused silica capillary was used as the spraying capillary and a voltage of $2.8 \mathrm{kV}$ was applied. The instrument was scanned from $\mathrm{m} / \mathrm{z} 500-2500$, $4 \mathrm{~s}$ per scan, and selected ion monitoring was used for $\mathrm{m} / \mathrm{z}$ 204, 274, 292, and 366 (0.5 s dwell time per ion).

\section{Results and Discussion}

When a glycoprotein contains multiple glycosylation sites, or where glycan structures are very heterogeneous, precursor ion scanning for ions fragmenting to give terminal or internal saccharide ions can detect all glycopeptides in a digest mixture [11]. Confirming the identity of the peptide moiety and determining the structure of the carbohydrate are essential and generally require a multifaceted approach. This can involve product ion scans of individual glycopeptide ions and/or peptide separation and various steps of exogly- 


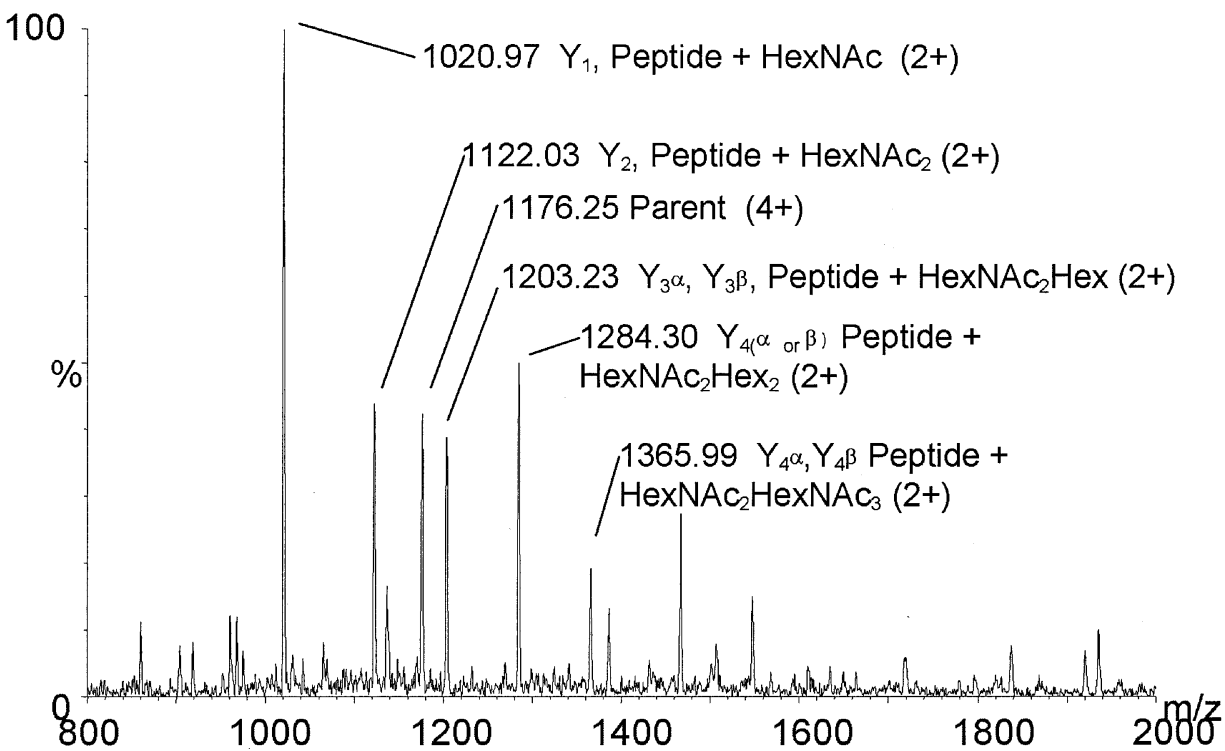

Figure 3. Product ion scan $(m / z$ 800-2000) of the trisialylated tri-antennary on the Leu 127-Arg 141 peptide (sequence LBPDBPLLAPLNDSR where B = vinyl pyridine cysteine; peptide mass 1837.2 Da) showing carbohydrate core structures common to all glycopeptides at this site. Only the doubly charged ion series is labeled. For fragmentation nomenclature see Figure 4.

cosidase digestion followed by repeat analyses, procedures that can be both time and sample consuming [13, 17]. Under normal CAD conditions, glycopeptides fragment predominately within the carbohydrate moiety producing $\mathrm{Y}$ - and B-type fragment ions (nomenclature as Domon and Costello [18]). Since $Y_{1}$ (or $\left.Y_{1 \alpha}, Y_{1 \beta}\right)$ ions (peptide plus the reducing terminal GlcNAc) will have the same mass for all glycopeptides that have the same peptide moiety, such ions can be used as diagnostic fragment ions. Thus, we believed that precursor ion scans for ions that fragment to give a particular $Y_{1}$ ion could selectively detect glycopeptides from a common glycosylation site. We have tested this hypothesis using an unseparated tryptic digest of fetuin, a $37 \mathrm{kDa}$ protein that has three sites of N-linked glycosylation (Asn 81, Asn 138, Asn 158) and various sites of O-linked glycosylation (Ser 253, Thr 262, Ser 264). The glycans are heterogeneous and this protein therefore provides a good substrate for development of the methodology, not least because the carbohydrates attached have previously been well characterized.

\section{Fetuin Glycan Characterization}

A tryptic digest of fetuin from fetal calf serum was desalted using a Zip-Tip (Millipore), eluted with 50\% (vol/vol) acetonitrile with $0.05 \%$ (vol/vol) formic acid and the peptide pool analyzed by nanospray-MS. The mass spectrum of this mixture is shown in Figure 2a, from which various tryptic peptides can be identified by comparison to a theoretical digest from the protein sequence. These are labeled in Figure $2 \mathrm{a}$ with the residue numbers. By comparison to known fetuin glycosylation, a number of putative glycopeptides could also be identified [10]. A precursor ion scan at $m / z 204$ $\left(\mathrm{HexNAc}^{+}\right)$selectively detected glycopeptides from the tryptic peptide mixture and is shown in Figure $2 \mathrm{~b}$. The spectrum includes peaks from a range of glycopeptides, many of which, although of low intensity, can be observed in the standard mass spectrum. The majority of the glycopeptide peaks also have associated peaks caused by sodium adduction, the relevance of which will become clear later. The precursor ion spectrum has signals from all glycosylation sites (N-linked and Olinked) contained within the protein and, at each site, the carbohydrate structures are heterogeneous. This 2 -fold heterogeneity accounts for the complexity of the spectrum, and also indicates the necessity to characterize each glycopeptide fully.

The most abundant glycopeptide ion, at $\mathrm{m} / \mathrm{z} 1176$, was chosen for product ion scanning and the CAD mass spectrum of this ion is shown in Figure 3. The spectrum contains predominately high $\mathrm{m} / \mathrm{z}$ Y type fragment ions as well as small, low $\mathrm{m} / \mathrm{z}$ B ions (this part of the spectrum is not shown) indicative of fragmentation within the carbohydrate. The peptide portion of the ion does not appear to fragment at all. The doubly charged $\mathrm{Y}$ type fragment ions reveal the sequence of the pentasaccharide core of the carbohydrate (shown in Figure 1), but other fragment ions also allow some outer arm structures to be elucidated. The $\mathrm{Y}_{1}^{2+}$ ion, at $\mathrm{m} / \mathrm{z} 1020$ (peptide and the reducing terminal GlcNAc) is the most abundant Y-type fragment ion in the spectrum and this ion confirms the identity of the peptide portion of the glycopeptide and thus the site of glycosylation, in this case Asn 138 (for peptide sequences and masses see figure legends). Enzymatic removal of the glycan chain with PNG'ase confirmed this assignment by measuring 


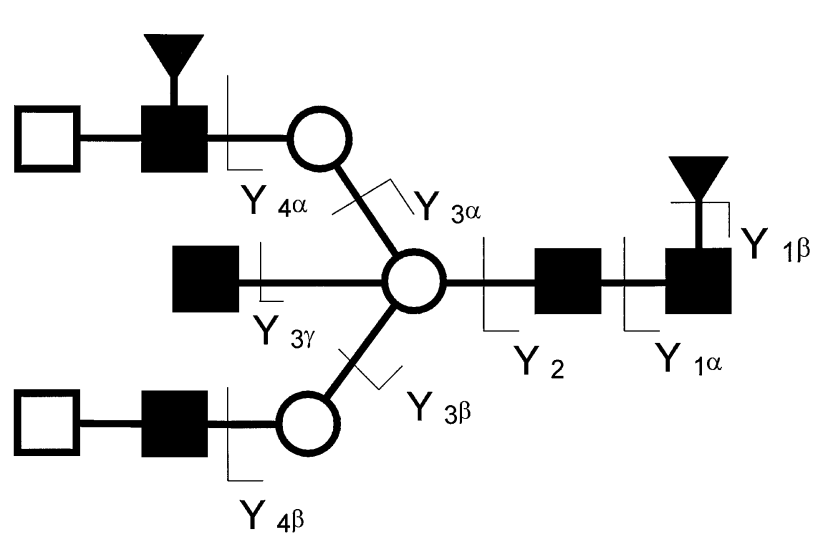

Figure 4. Fragmentation nomenclature of a glycopeptide (only carbohydrate moiety shown) as Domon and Costello [Domon B, 1988 no. 87]. Y type fragmentation ions always include the intact peptide. Key to structures: Filled square GlcNAc, open square galactose, open circle mannose, filled inverted triangle fucose.

the mass of the resultant peptide (data not shown). The $\mathrm{Y}_{1}^{2+}$ ion and the four other $\mathrm{Y}$ ions shown are common fragment ions for all N-linked glycopeptides at this site. Thus, precursor ion scanning for any of these ions will selectively detect glycopeptides that have the same peptide portion whilst not detecting glycopeptides from other glycosylation sites.

Using identical fragmentation conditions, a precursor ion scan was used to detect all ions that fragmented to give the $\mathrm{Y}_{1}^{2+}$ ion (peptide + HexNAc) ${ }^{2+}$ at $\mathrm{m} / \mathrm{z} 1020$. The resulting spectrum is shown in Figure $5 \mathrm{a}$ and has signals corresponding to six different glycopeptides, all of which share the same peptide sequence, but which differ in the carbohydrate structure. The inherent sensitivity of this mode of scanning allows the resolution of the instrument to be increased, leading to better resolved peaks. The level of background noise from which the glycopeptides are detected is evident from the peak at $\mathrm{m} / \mathrm{z}$ 1020, which represents chemical noise passed at the fragment ion $\mathrm{m} / \mathrm{z}$ without fragmentation. The glycopeptides are detected well above the noise level for this spectrum and it is interesting to note that the efficiency of detection of sodiated glycopeptides is dramatically reduced in this spectrum, compared to both the standard MS1 and $\mathrm{m} / \mathrm{z}$ 204 precursor ion scan, the rationale for which will be discussed later in the PrP section. This enables a more equivocal measure of the mass of the glycopeptide and allows carbohydrate compositions to be assigned unambiguously. The glycopeptides represent six structures, some of which have been detected previously at the Asn 138 site. These structures are listed in Table 1 . An additional ion was also observed at $\mathrm{m} / \mathrm{z} 878$, the mass of which did not correspond to a possible glycopeptide ion. CAD of this ion demonstrated that this is the N-terminal tryptic peptide spanning the first 32 residues of fetuin and the product ion spectrum included a weak $\mathrm{z}$ ion of $m / z 1020$, rationalizing its appearance in the $m / z 1020$ precursor ion scan.

Characterization of the Asn 138 site enables these peptides to be identified in the initial precursor ion scan for $m / z 204$, and hence also allowed the identification of glycopeptides from other sites. Sequentially, other glycopeptides were selected for CAD analysis, which again revealed common $\mathrm{Y}$ ions for precursor ion scanning and allowed specific detection of glycopeptides from one of the other N-linked sites (Asn 81, Figure 5b), and the glycopeptides including the O-linked sites (Figure $5 \mathrm{c}$ ). In each case, the $\mathrm{Y}_{1}^{2+}$ fragment ions, (peptide + HexNAc), were chosen for precursor ion scanning since they were typically the most abundant Y-type fragment ions. This approach will work for all N-linked sites, since the reducing terminal sugar is always $\mathrm{N}$-acetylglucosamine (GlcNAc). The O-linked glycans detected in this case all have $\mathrm{N}$-acetylgalactosamine (GalNAc) at their reducing termini, which is an epimer of GlcNAc and therefore has the same mass.

Glycopeptides from the remaining N-linked glycosylation site, Asn 158, gave low intensity signals in both the MS1 scan and the precursor ion scan for $m / z 204$. Additionally, potential $\mathrm{Y}$ ions for scanning coincided with stronger signals from other sites making analysis of glycopeptides from this site problematic without prior concentration/purification. The tryptic digest was partially fractionated by HPLC, and redissolved in 50\% (vol/vol) acetonitrile and $0.05 \%$ (vol/vol) trifluoroacetic acid to promote the formation of higher $\mathrm{m} / \mathrm{z}$ ions. A lower charge state $Y_{1}$ fragment ion was chosen for precursor ion scanning and this resulted in a good precursor ion scan, the quality of which was comparable to that of the other sites. The precursor ion mass spectrum for site Asn 158 is shown in Figure 5d. Glycopeptides detected at this site were more heterogeneous than previously detected and this may have contributed to the detection problems encountered. The increased heterogeneity could be the product of sample degradation or of cone voltage mediated dissociation, but the lack of these effects at the other sites suggests that these results are not artefactual.

The full range of carbohydrates detected on fetuin by this novel methodology is shown in Table 1. Although slightly more heterogeneous, they agree well with previously published data $[10,19,20]$. The N-linked structures have up to three antennae and up to four sialic acid moieties. In the trianntennary, tetrasialylated species one sialic acid appears to be $\alpha 2-6$ linked to $\mathrm{N}$ acetylglucosamine rather than the more common $\alpha 2-6$ linkage to galactose. This linkage cannot be ruled out in the other structures, and may be present in the sialylated Structure $\mathrm{g}\left(\mathrm{Hex}_{3} \mathrm{HexNAc}_{3} \mathrm{NeuAc}_{1}\right)$, the composition of which (confirmed by product ion scanning) suggests a structure without any galactose. Alternatively, the trimannosyl core may not be intact, and a single galactose-containing arm may be sialylated in the more common manner. It is difficult to resolve this by low energy CAD experiments since galactose and mannose have the same mass. O-linked glycosylation on the peptide spanning Val 228-Arg 288 is reported as carbohydrate compositions and is again slightly more heterogeneous than previously published MS data [10]. 


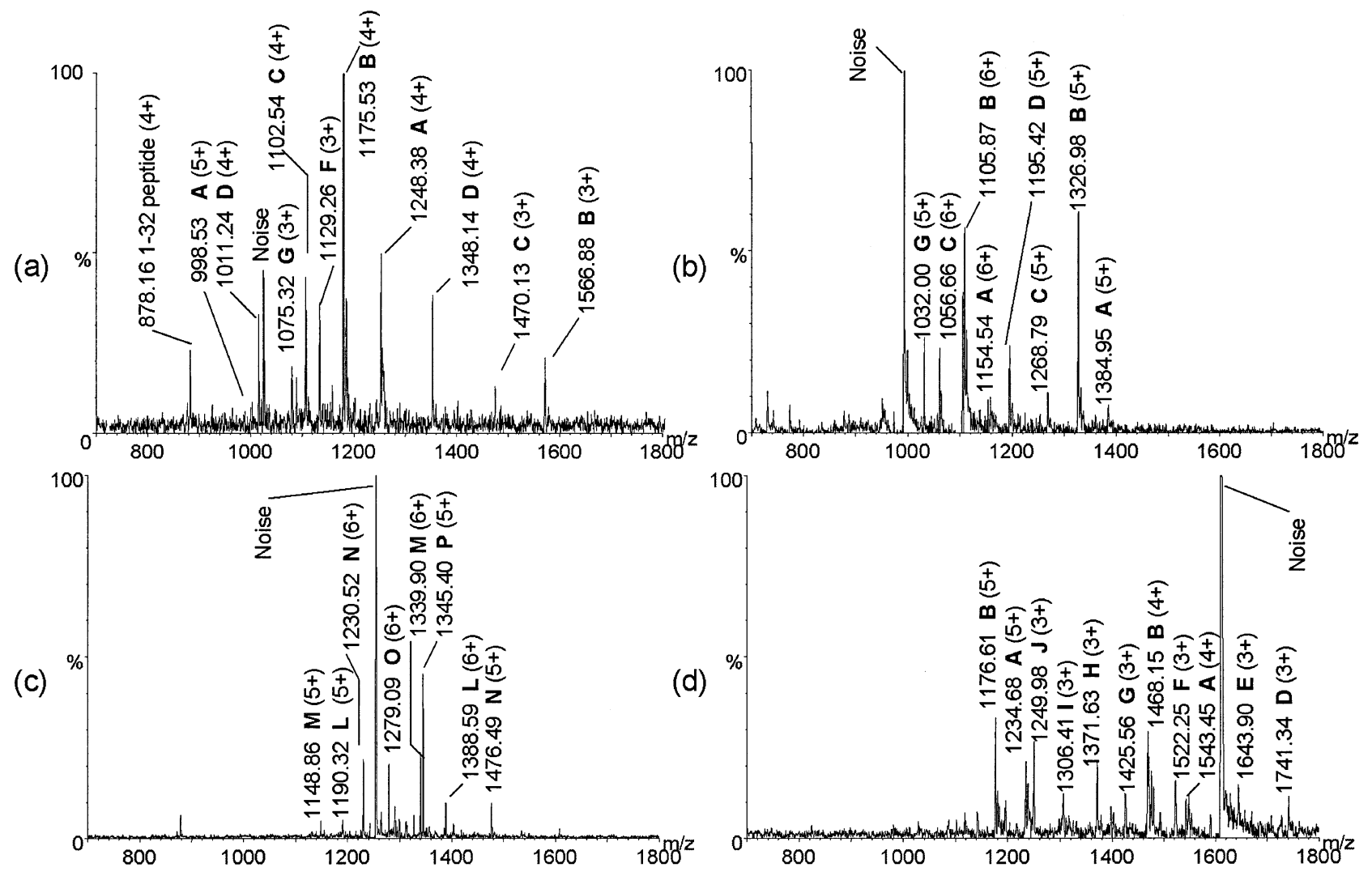

Figure 5. Fetuin glycopeptides detected by precursor ion scanning of an unseparated peptide mixture, unless otherwise noted. All scans are at the mass/charge of an ion for the glycosylation site peptide + HexNAc. Glycan structure on the peptide is indicated in the table below. (a) Precursors of $\mathrm{m} / \mathrm{z} 1020.70(2+)$; a scan for glycosylation on the L127-R141 peptide (sequence LBPDBPLLAPLNDSR where B = vinyl pyridyl cysteine; aglycosyl peptide mass 1837.2 Da). (b) Precursors of $m / z 993.60(4+)$; a scan for glycosylation on the R54-R85 peptide (sequence RPTGEVYDIEIDTLETTBHVLDPTPLANBSVR where B = vinyl pyridyl cysteine; aglycosyl peptide mass $3769.3 \mathrm{Da}$ ). (c) Precursors of $\mathrm{m} / \mathrm{z}$ 1254.20 (6+); a scan for O-linked glycosylation on the V228-R288 peptide (peptide mass 6066.0 Da). (d) Precursors of $\mathrm{m} / \mathrm{z} 1610.50(2+)$; a scan for glycosylation on the V142-R169 peptide (sequence VVHAVEVALATFNAESNGSYLQLVEISR; aglycosyl peptide mass 3017.4 Da) on a HPLC separated fraction. The peak labeled "noise" in each case is at the mass/charge of the precursor ion, and represents the non-specific passing of chemical background noise at that mass/charge ratio.

No attempt was made to elucidate the structure of these carbohydrates.

\section{Prion Protein $\left(\operatorname{PrP}^{S c}\right)$}

The prion protein, $\operatorname{PrP}$ is a cell membrane bound glycoprotein of approximately 210 amino acids and an unmodified mass of around $23 \mathrm{kDa}$. Post translational modifications include two Asn-linked glycosylation sites [14, 15], a GPI anchor [21], a single disulphide bond [22], and partial proline hydroxylation near the $\mathrm{N}$-terminus [23]. The glycosylation of the prion protein has been suggested to play a fundamental role in the transmissible spongiform encephalopathies (TSEs) [2426]. Crucially occupancy of the $2 \mathrm{~N}$-linked glycosylation sites varies depending on the strain of TSE disease [27] and blockade of glycosylation of $\operatorname{PrP}$ can promote scrapie-like pathogenesis in cultured cells [24]. Differences in the structures of individual carbohydrates have also been observed between the normal, $\operatorname{PrP}^{\mathrm{C}}$, and diseased $\operatorname{PrP}^{\mathrm{Sc}}$ isoforms of the protein [15]. Although there were no gross differences in carbohydrate structures, $\mathrm{PrP}^{\mathrm{Sc}}$ had fewer saccharides containing bisecting GlcNAc moieties, consistent with down regulation of the saccharide transferase enzyme GnT III during disease pathogenesis. A method for rapid and sensitive elucidation of these carbohydrate structures and comparison of glycopeptide profiles is of paramount importance for future work in this area. Although the Nlinked carbohydrates at the two sites on $\operatorname{PrP}$ are more heterogeneous than those of fetuin $[3,14,15,28]$, our precursor ion scanning methodology should be applicable. Glycans from rodent neural tissues may carry the bisecting GlcNAc motif, fucosylation at the reducing terminal GlcNAc (core), and outer arm GlcNAcs (Lewis X epitope) are typical $[29,30]$, although sialylation is not as common as in fetuin. These features are shown in Figure 1 and the structural complexity necessitates 
Table 1a. N-linked glycans detected on fetuin by precursor ion scanning

\begin{tabular}{|c|c|c|c|c|}
\hline Label & $\begin{array}{c}\text { Glycan } \\
\text { structure }^{a}\end{array}$ & $\begin{array}{l}\text { L127-R141 } \\
\text { peptide } \\
\text { (a) }\end{array}$ & $\begin{array}{l}\text { R54-R85 } \\
\text { peptide } \\
\text { (b) }\end{array}$ & $\begin{array}{l}\text { V142-R169 } \\
\text { peptide } \\
\text { (d) }\end{array}$ \\
\hline A & 政 & $\sqrt{ }$ & $\checkmark$ & $\checkmark$ \\
\hline B & & $\checkmark$ & $\checkmark$ & $\checkmark$ \\
\hline C & & $\sqrt{ }$ & $\sqrt{ }$ & \\
\hline D & & $\checkmark$ & $\checkmark$ & $\checkmark$ \\
\hline$E$ & & & & $\checkmark$ \\
\hline$F$ & & $\checkmark$ & & $\checkmark$ \\
\hline G & & $\sqrt{ }$ & $\checkmark$ & $\checkmark$ \\
\hline $\mathrm{H}$ & & & & $\checkmark$ \\
\hline I & & & & $\checkmark$ \\
\hline $\mathrm{J}$ & & & & $\checkmark$ \\
\hline
\end{tabular}

aKey to structures: GIcNAc, $\square$ Galactose, O Mannose, 0 NeuAc.

considerably more characterization than is the case with fetuin glycans; structure-specific precursor ion scans may be used to aid characterization.

\section{Specific Detection of Glycosylation at the Asn 181 Site}

Purified PrP was reduced, alkylated and digested with trypsin. The peptide pool was desalted by use of a Zip-Tip and an MS 1 scan of this (Figure 6a) includes a variety of peaks corresponding to tryptic peptides. Due to the heterogeneity of the glycoforms, the abundance of any glycopeptide ion will be low relative to the more intense peptide signals, hence peaks corresponding to

Table 1b. O-linked glycans detected on fetuin by precursor ion scanning

\begin{tabular}{lc}
\hline Label & Composition \\
\hline \hline $\mathrm{L}$ & $\mathrm{Hex}_{3} \mathrm{HexNAc}_{3} \mathrm{NeuAC}_{4}$ \\
$\mathrm{M}$ & $\mathrm{Hex}_{3} \mathrm{HexNAc}_{3} \mathrm{NeuAC}_{3}$ \\
$\mathrm{~N}$ & $\mathrm{Hex}_{2} \mathrm{HexNAc}_{2} \mathrm{NeuAC}_{2}$ \\
$\mathrm{O}$ & $\mathrm{Hex}_{2} \mathrm{HexNAc}_{2} \mathrm{NeuAC}_{3}$ \\
$\mathrm{P}$ & $\mathrm{Hex}_{1} \mathrm{HexNAc} \mathrm{NeuAC}_{1}$ \\
\hline
\end{tabular}

Table 2. Structure of carbohydrates on $\mathrm{Y}$ ions from Figure 7

\begin{tabular}{|c|c|c|c|}
\hline Label & Fragment Ion & Composition & $\begin{array}{l}\text { Structure of } \\
\text { glycan }^{\mathrm{a}, \mathrm{b}}\end{array}$ \\
\hline A & $Y_{1 \alpha}, Y_{1 \beta}$ & HexNAc & d \\
\hline B & $Y_{1 \alpha}$ & HexNAcFuc & \\
\hline C & $\mathrm{Y}_{2}, \mathrm{Y}_{1 \beta}$ & $\mathrm{HexNAc}_{2}$ & \\
\hline D & $Y_{2}$ & $\mathrm{HexNAc}_{2}$ Fuc & \\
\hline$E^{d}$ & $Y_{3 \alpha^{\prime}} Y_{3 \beta}\left(Y_{3 \gamma}\right)$ & $\mathrm{HexHexNAc}{ }_{2}$ Fuc & \\
\hline $\mathrm{F}$ & $\begin{array}{c}\mathrm{Y}_{3 \times \prime}, \mathrm{Y}_{4 x}, \mathrm{Y}_{1 \beta} \\
\left(\mathrm{Y}_{3 \gamma}\right)\end{array}$ & $\mathrm{Hex}_{2} \mathrm{HexNAc}_{2}$ & \\
\hline G & $Y_{3 \alpha^{\prime}} Y_{3 \beta^{\prime}} Y_{1 \beta}$ & $\mathrm{HexHexNAc}{ }_{3}$ & \\
\hline $\mathrm{H}$ & $Y_{3 x}, Y_{4 x},\left(Y_{3 \gamma}\right)$ & $\mathrm{Hex}_{2} \mathrm{HexNAc}_{2}$ Fuc & \\
\hline$I^{\mathrm{c}}$ & $\begin{array}{c}\mathrm{Y}_{4 \alpha^{\prime}} \mathrm{Y}_{4 \beta^{\prime}} \mathrm{Y}_{1 \beta^{\prime}} \\
\left(\mathrm{Y}_{3 \gamma}\right)\end{array}$ & $\mathrm{Hex}_{3} \mathrm{HexNAc}_{2}$ & \\
\hline J & $Y_{3 \alpha}, Y_{3 \beta}$ & $\mathrm{HexHexNAc}{ }_{3}$ Fuc & \\
\hline K & $?$ & $\mathrm{Hex}_{2} \mathrm{HexNAc}_{3}$ & Indeterminable ${ }^{\mathrm{e}}$ \\
\hline $\mathrm{L}^{\mathrm{c}}$ & $\mathrm{Y}_{4 \alpha^{\prime}} \mathrm{Y}_{4 \beta}\left(\mathrm{Y}_{3 \gamma}\right)$ & $\mathrm{Hex}_{3} \mathrm{HexNAc}_{2} \mathrm{Fuc}$ & \\
\hline M & $?$ & $\mathrm{Hex}_{2} \mathrm{HexNac}_{3} \mathrm{Fuc}$ & Indeterminable ${ }^{\mathrm{e}}$ \\
\hline
\end{tabular}

${ }^{\text {a }}$ For key to glycopeptide fragmentation nomenclature see Figure 4. Peptide is the Tyr 157-Lys185 peptide (mass $=3665.06$ ).

bKey to structures: G GlcNAc, $\square$ galactose, $\bigcirc$ mannose, $\checkmark$ fucose. cFragment ions $I$ and $L$ are not designated as $Y_{3 \gamma}$ cleavage as they are thought to be products of structures not containing bisecting GIcNAc. dWith fragment ion $E$, the parent ion is undetermined hence the occurrence of the $Y_{3 \gamma}$ cleavage is also undetermined.

eStructures labeled as indeterminable could be one of several possible structures for the given composition.

glycopeptide ions are not obvious in the MS1 scan. A glycosylation specific precursor ion scan for HexNAc at $\mathrm{m} / \mathrm{z} 204$ (Figure $6 \mathrm{~b}$ ) reveals all glycopeptides from the two sites (Asn 181 and Asn 197). From this scan the heterogeneity of glycosylation is evident.

As with the fetuin, a high $\mathrm{m} / \mathrm{z}$ fragment ion from a glycopeptide is required for specific detection of glycosylation at a given site and is derived from CAD of a selected glycopeptide. A product ion scan on the most abundant glycopeptide ion $(\mathrm{m} / \mathrm{z} 1406)$, showed many fragment ions including a dominant doubly charged $Y$ ion series (Figure 7a). The $Y_{1 \alpha}, Y_{1 \beta}$ ion for [peptide + $\mathrm{GlcNAc}^{2+}$, a fragment ion specific to all glycosylated forms of this peptide (the designation $Y_{1 \alpha}, Y_{1 \beta}$ assumes core fucosylation of the glycan) is evident. This data also revealed that the carbohydrate was attached to the 157-185 peptide (for peptide sequences and masses see figure legends), an observation that was confirmed by measuring the mass of peptide released after enzymatic deglycosylation with PNG'ase. The composition of this 

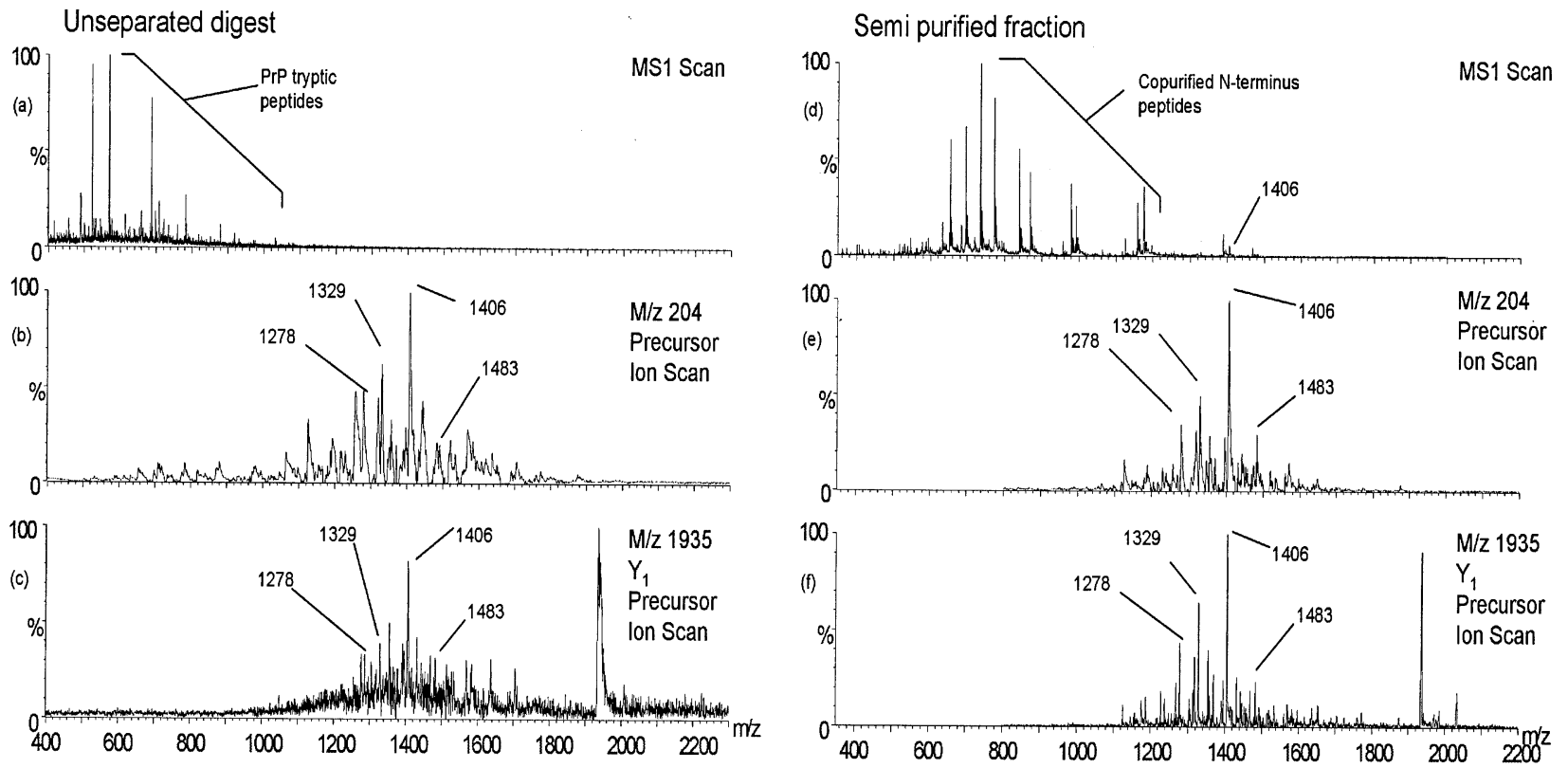

Figure 6. Mass spectra of $\operatorname{PrP}^{\mathrm{Sc}}$ tryptic digest, desalted by Zip-Tip $(\mathbf{a}, \mathbf{b}, \mathbf{c})$ or partially purified HPLC fraction containing the Asn 181 site (d,e,f). (a) and (d) MS1 scans. (b) and (e) precursor ion scan at $m / z$ 204 for the immonium ion of HexNAc. (c) and (f) precursor scan at $m / z 1934.5$ for the $Y_{1}$ ion of the Asn181 peptide + HexNAc (sequence YPNQVYYRPVDQYNNQNNFVHDBVNITIK; aglycosyl peptide mass $3665.1 \mathrm{Da}$ ). Note that only the most intense glycopeptide ion [1406 (4+)] is visible on only the MS1 of the HPLC fraction. Also, the level of the $\mathrm{m} / z 1935$ noise peak is well above many of the detected glycopeptides. Selected $\mathrm{m} / \mathrm{z}$ are labeled.

glycan was found to be that of the most abundant glycan identified by two previous studies [14, 15].

The $\left(Y_{1 \alpha}, Y_{1 \beta}\right)^{2+}$ ion at $m / z 1935$ was used in a site specific precursor ion scan to detect all Asn 181 glycopeptides (Figure 6c). By comparison with Figure 6b, it can be seen that the majority of ions detected in the $\mathrm{m} / \mathrm{z}$ 204 scan appear to result from glycopeptides at the 181 site. As expected, the more specific $m / z 1935$ scan was of markedly increased quality compared with the $m / z 204$ scan. The sensitivity of the $\mathrm{m} / \mathrm{z} 1935$ precursor ion scan is illustrated by the comparison to the noise peak at $\mathrm{m} / \mathrm{z}$ 1935, suggesting that glycopeptides were present at levels of low fmole/ $\mu$ l. Despite the better quality spectrum, however, improvements in terms of signal to noise ratio and resolution were still desirable. The $\operatorname{PrP}^{\mathrm{Sc}}$ tryptic peptides were separated by HPLC and fractions containing the glycopeptides were collected. Figure 6d shows an MS1 scan of the fraction containing the Asn 181 site glycopeptides. Co-purifying, non-glycosylated peptides are still evident, and two peptides from the $\mathrm{N}$ terminus (residues 49-106, theoretical mass 5872.2 Da; residues 38-106, theoretical mass $6943.3 \mathrm{Da}$ ) are prominent. An $m / z 204$ precursor ion scan (Figure 6e) confirmed the major glycopeptide ion at this site to be $\mathrm{m} / \mathrm{z}$ $1406\left(4^{+}\right)$and an $\mathrm{m} / z 1935$ precursor ion scan (Figure 6f) again produced a spectrum superior in quality to the $\mathrm{m} / \mathrm{z} 204 \mathrm{~B}$ ion scan.

The high $m / z Y_{1 \alpha}, Y_{1 \beta}$ precursor ion scans consistently have better signal to noise ratios and improved resolution over the low $\mathrm{m} / \mathrm{z}$ B ion scans. This may be because higher $\mathrm{m} / \mathrm{z}$ ions are less common from a fragmentation so are less likely to be the product of an interfering non-glycopeptide molecule, whereas low $\mathrm{m} / \mathrm{z}$ precursor ion scans tend to include more interference from non-glycopeptide ions. In addition, in B ion precursor ion scans, where a glycopeptide has a cation adducted (most typically sodium ions), both the glycopeptide and the equivalent adduct ions are detected (see Figure 2), presumably because the cation attaches via the peptide moiety. With $Y_{1}$ ion precursor scans, adduction on the peptide will produce adducted $Y_{1}$ ions of increased mass, which will not be detected in a $Y_{1}$ ion precursor ion scan. This will decrease peak width when using lower MS1 resolution necessary for the detection of weak signals, hence aid glycopeptide identification during precursor ion scanning. This is illustrated with the fetuin data, when adducted species detected in the MS1 and $m / z 204$ precursor scans are not seen in the $Y_{1}$ precursor ion scan.

\section{Characterization of Glycans at the Asn 181 Site}

Ions detected in the $Y_{1 \alpha}, Y_{1 \beta}$ precursor ion scans were used to obtain masses of the glycopeptides and, by subtraction of the peptide mass, masses of the glycans present at this site. These measurements were then related to the glycan composition, and are shown in Table 3. Elucidation of the branching structure of the glycan, which cannot always be determined by composition alone, is dependent upon the detection of a 

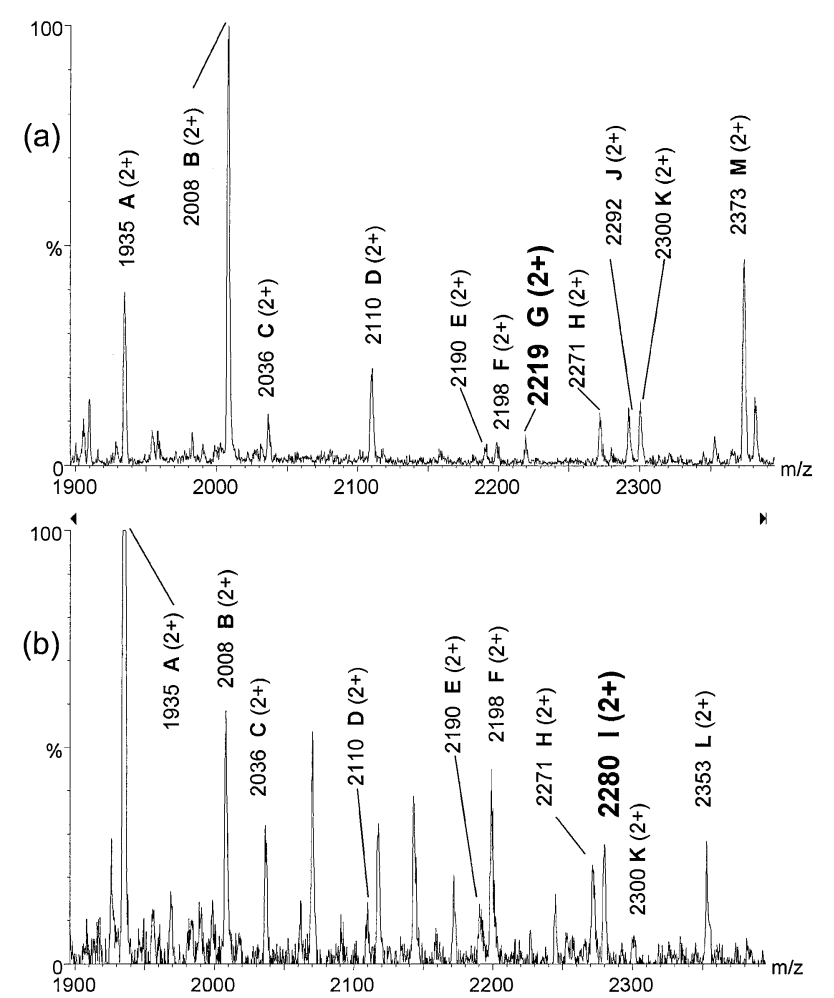

Figure 7. Q-TOF product ion scans of $\mathrm{PrP}^{\mathrm{Sc}}$ Asn181 glycopeptide ions. Doubly charged $\mathrm{Y}$ ion series labeled only. For ion identity see Table 3. Ions indicative of structural characteristics are labeled in bold large font; G m/z 2219 (2+) indicative of bisecting GlcNAc, I $\mathrm{m} / \mathrm{z} 2280(2+)$ indicative of structure free of bisecting GlcNAc. (a) Parent ion at $\mathrm{m} / \mathrm{z} 1406$, a glycopeptide ion heterogeneous in bisecting GlcNAc structure. (b) Parent ion at $m / z$ 1396, a glycopeptide ion for a structure with no bisecting GlcNAc present.

bisecting GlcNAc (GlcNAc to the core mannose) (see Figure 1). In some cases the carbohydrate composition will indicate that a bisecting GlcNAc is not possible, e.g., where the number of hexoses exceed the number the number of HexNAcs by one. In these cases the antennae are fully galactosylated, and no GlcNAcs are left over to be attached to the mannose by a $\beta 1-4$ linkage. In other cases (where the number of hexoses is less than or equal to the number of HexNAcs) the structure is not clear. The presence of bisecting GlcNAc has previously been shown to be relevant in $\mathrm{PrP}^{\mathrm{Sc}}$. In a comparative study of the glycoforms of the normal and diseased forms of the protein, it was observed that the diseased form possessed decreased levels of glycans containing bisecting GlcNAcs [15].

The product ion scan of the $m / z 1406$ ion, shown previously to contain bisecting GlcNAc $[14,15]$ included an ion resulting from $\mathrm{Y}_{3 \alpha}, \mathrm{Y}_{3 \beta}$ fragmentation, which can be assigned the structure [peptide + Hex$\left.\mathrm{HexNAc}_{3}\right]^{2+}$. This ion, at $m / z 2219$, is the product of $\mathrm{Y}$ type fragmentation across mannose-mannose $\alpha 1-6$ and $\alpha 1-3$ bonds (i.e, loss of both branches) leaving the $\beta 1-4$ linked bisecting GlcNAc intact. It is diagnostic for bisecting GlcNAc structure and common to all glycans that carry this motif attached to the 157-185 glycopep- tide, therefore precursor ion scanning for this ion will detect glycopeptide ions containing bisecting GlcNAc. The possibility exists, however, of isomeric glycopeptides either having or not having bisecting GlcNAc. The product ion scan of a non-bisected glycopeptide of mass $5580.4 \mathrm{Da}$ (Figure7b) suggested that the fragment ion [peptide $\left.+\mathrm{Hex}_{3} \mathrm{HexNAc}_{2}\right]^{2+}\left(\mathrm{Y}_{4 \alpha}, \mathrm{Y}_{4 \beta}\right)^{2+}$ was an ion exclusive to non-bisecting glycopeptides and precursor ion scanning for this ion would detect glycopeptide ions not having bisecting GlcNAc. Observations from previously published data help to support this. In studies on the fragmentation of glycans containing bisecting GlcNAc it was seen that: (1) The $Y$ ion series of loss of outer arm GlcNAcs ends before the loss of the final GlcNAc [31] and (2) the outer mannose moieties will dissociate in preference to the bisecting GlcNAc [32]. From this it would appear that the $Y$ type fragment ion of peptide + $\mathrm{Hex}_{2} \mathrm{HexNAc}_{3}$ is unlikely to arise from CID of glycopeptides with bisecting GlcNAcs.

The two doubly charged ions at $\mathrm{m} / \mathrm{z} 2280$ and 2219 were used for precursor ion scanning for structural characterization of glycopeptides. These scans are shown in Figure 8. An additional scan at $m / z 1480$ (for [peptide $+\mathrm{HexNAc}_{3} \mathrm{Hex}^{3+}$ ) was used to confirm the presence of bisecting GlcNAc (not shown). It is immediately apparent that more ions appear in the $\mathrm{m} / \mathrm{z} 2280$ (no bisecting GlcNAc) scan, indicating a greater number of structures without the bisecting GlcNAc motif. Some ions are unique to one scan indicating homogeneity of structure for a glycopeptide (e.g., masses 5580.4 and $5766.6 \mathrm{Da}$ ). Some ions appear in both scans, indicating two isomeric structures for a single glycopeptide ion (e.g., glycopeptides of mass 5621.7 and $5313.3 \mathrm{Da}$ ). As with the $m / z 1935$ precursor ion scan, the strongest peak is at $m / z 1406$, and the majority of strong signals are from the ions carrying four positive charges. With reference to Figure 7, it is evident that the structural fragment ions being scanned for are of weaker intensity than the $Y_{1 \alpha}, Y_{1 \beta}$ ions used for initial glycopeptide detection. This reduces the intensity of the structural precursor ion scans compared to the $Y_{1}$ precursor scan and necessitates the use of lower resolution to increase sensitivity, hence these scans do not give accurate mass data, but are only indicative of ions in the $Y_{1}$ scan.

To provide additional information on outer arm structures, precursor ion scans for $\mathrm{B}$ ions indicative of the Lewis X epitope ([HexHexNAcFuc $\left.+\mathrm{H}]^{+}=m / z 512\right)$ and sialic acid $(m / z 274 / 292)$ may be used. These will largely resolve glycopeptides that are close in mass in cases when the composition is not clear. The B ion scan at $\mathrm{m} / \mathrm{z} 512$ for Asn181 glycopeptides containing the Lewis X epitope is shown in Figure 9. This spectrum has broad peaks and suffers from the lack of resolution encountered with B ion scanning, hence is used only as an indication of the presence of the Lewis $X$ epitope. From this data it was possible to resolve multiply fucosylated species from sialylated species in instances where no more than three fucoses or one sialic acid were present. With a larger number of potential moi- 
Table 3. Glycopeptides from $\operatorname{PrP}^{\mathrm{Sc}}$ detected and characterised by precursor ion scanning

\begin{tabular}{|c|c|c|c|c|c|c|c|c|c|c|}
\hline \multirow[b]{2}{*}{$\operatorname{lons}^{a}$} & \multicolumn{3}{|c|}{ Precursor ion scans ${ }^{b}$} & \multicolumn{2}{|c|}{ Mass of glycopeptide } & \multicolumn{4}{|c|}{ Composition $^{g}$} & \multirow[b]{2}{*}{ Structure $(s)^{\mathrm{h}}$} \\
\hline & $\begin{array}{c}m / z \\
2219\end{array}$ & $\begin{array}{c}m / z \\
2280\end{array}$ & $\begin{array}{l}m / z \\
512\end{array}$ & Measured & Calculated & Hex & HexNAc & Fuc & NeuAc & \\
\hline $\begin{array}{l}1278.4(4+) \\
1704.4(3+)\end{array}$ & $\sqrt{ }^{\mathrm{c}}$ & $\checkmark$ & $X^{d}$ & 5109.80 & 5110.42 & 3 & 4 & 1 & 0 & 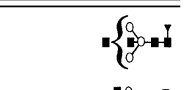 \\
\hline $\begin{array}{l}1319.2(4+) \\
1758.1(3+)\end{array}$ & $\checkmark$ & $\checkmark$ & $x$ & 5271.93 & 5272.56 & 4 & 4 & 1 & 0 & \\
\hline $\begin{array}{l}1063.4(5+) \\
1329.4(4+) \\
1772.3(3+)\end{array}$ & $\checkmark$ & $\checkmark$ & $x$ & 5313.26 & 5313.62 & 3 & 5 & 1 & 0 & \\
\hline $\begin{array}{l}1084.6(5+) \\
1355.4(4+) \\
1807.1(3+)\end{array}$ & $\checkmark$ & $\checkmark$ & $\checkmark$ & 5418.13 & 5418.70 & 4 & 4 & 2 & 0 & \\
\hline $\begin{array}{l}1359.6(4+) \\
1088.0(5+)\end{array}$ & $x$ & $\sqrt{ }$ & $x$ & 5433.90 & 5434.7 & 5 & 4 & 1 & 0 & \\
\hline $\begin{array}{l}1096.3(5+) \\
1369.9(4+) \\
1826.4(3+)\end{array}$ & $\checkmark$ & $\checkmark$ & $x$ & 5475.74 & 5475.76 & 4 & 5 & 1 & 0 & \\
\hline $\begin{array}{l}1117.1(5+) \\
1396.1(4+)\end{array}$ & $x$ & $\sqrt{ }$ & $\sqrt{ }$ & 5580.40 & 5580.84 & 5 & 4 & 2 & 0 & 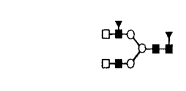 \\
\hline $\begin{array}{l}1125.4(5+) \\
1406.3(4+) \\
1874.6(3+)\end{array}$ & $\sqrt{ }$ & $\checkmark$ & $\checkmark$ & 5621.72 & 5621.90 & 4 & 5 & 2 & 0 & \\
\hline $\begin{array}{l}1146.2(5+) \\
1432.5(4+)\end{array}$ & $x$ & $\checkmark$ & $x$ & 5725.92 & 5725.96 & 5 & 4 & 1 & 1 & \\
\hline $\begin{array}{l}1154.2(5+) \\
1442.8(4+)\end{array}$ & $x$ & $\checkmark$ & $\checkmark$ & 5766.55 & 5768.04 & 4 & 5 & 3 & 0 & \\
\hline $\begin{array}{l}1158.27(5+) \\
1447.0(4+)\end{array}$ & $x$ & $\checkmark$ & $\mathrm{Q}^{\mathrm{e}}$ & 5785.10 & $\begin{array}{l}5783.02 \\
5784.04\end{array}$ & $\begin{array}{l}5 \\
5\end{array}$ & $\begin{array}{l}5 \\
5\end{array}$ & $\begin{array}{l}0 \\
2\end{array}$ & $\begin{array}{l}1 \\
0\end{array}$ & \\
\hline $\begin{array}{l}979.7(6+) \\
1175.6(5+) \\
1468.8(4+) \\
1958.4(3+)\end{array}$ & $\checkmark$ & $\checkmark$ & $\checkmark$ & 5872.03 & $\begin{array}{l}5866.16 \#^{f} \\
5872.10\end{array}$ & $\begin{array}{l}3 \\
5\end{array}$ & $\begin{array}{l}7 \\
4\end{array}$ & $\begin{array}{l}2 \\
2\end{array}$ & $\begin{array}{l}0 \\
1\end{array}$ & 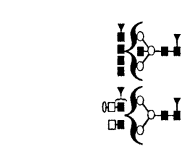 \\
\hline $\begin{array}{l}1183.0(5+) \\
1479.5(4+)\end{array}$ & $\checkmark$ & $\checkmark$ & Q & 5912.16 & 5913.16 & 4 & 5 & 2 & 1 & it \\
\hline $\begin{array}{l}1187.1(5+) \\
1483.2(4+) \\
1977.5(3+)\end{array}$ & $\checkmark$ & $x$ & $\sqrt{ }$ & 5929.13 & 5930.18 & 5 & 5 & 3 & 0 & 1. \\
\hline $\begin{array}{l}1194.8(5+) \\
1493.4(4+)\end{array}$ & $\checkmark$ & $x$ & Q & 5969.26 & $\begin{array}{l}5970.22 \\
5971.24\end{array}$ & $\begin{array}{l}4 \\
4\end{array}$ & $\begin{array}{l}6 \\
6\end{array}$ & $\begin{array}{l}1 \\
3\end{array}$ & $\begin{array}{l}1 \\
0\end{array}$ & is \\
\hline $\begin{array}{l}1216.1(5+) \\
1520.2(4+)\end{array}$ & $\checkmark$ & $x$ & $\sqrt{ }$ & 6076.14 & 6075.30 & 5 & 5 & 2 & 1 & \\
\hline $\begin{array}{l}1020.2(6+) \\
1227.8(5+) \\
1534.5(4+\end{array}$ & $\sqrt{ }$ & $\checkmark$ & $x$ & 6133.64 & 6132.36 & 5 & 6 & 1 & 1 & t \\
\hline
\end{tabular}


Table 3. Continued

\begin{tabular}{|c|c|c|c|c|c|c|c|c|c|c|}
\hline \multirow[b]{2}{*}{ lons $^{a}$} & \multicolumn{3}{|c|}{ Precursor ion scans ${ }^{b}$} & \multicolumn{2}{|c|}{ Mass of glycopeptide } & \multicolumn{4}{|c|}{ Composition $^{g}$} & \multirow[b]{2}{*}{ Structure $(\mathrm{s})^{\mathrm{h}}$} \\
\hline & $\begin{array}{c}\mathrm{m} / \mathrm{z} \\
2219\end{array}$ & $\begin{array}{c}\mathrm{m} / \mathrm{z} \\
2280\end{array}$ & $\begin{array}{l}\mathrm{m} / \mathrm{z} \\
512\end{array}$ & Measured & Calculated & Hex & HexNAc & Fuc & NeuAc & \\
\hline $\begin{array}{l}1047.5(6+) \\
1256.6(5+) \\
1569.9(4+)\end{array}$ & $\checkmark$ & $\mathrm{x}$ & $\sqrt{ }$ & 6277.54 & 6277.48 & 5 & 6 & 2 & 1 & og \\
\hline $\begin{array}{l}1268.4(5+) \\
1585.1(4+)\end{array}$ & $x$ & $\sqrt{ }$ & Q & 6336.79 & $\begin{array}{l}6335.56 \\
6336.58\end{array}$ & 5 & 7 & 3 & 0 & 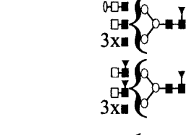 \\
\hline $\begin{array}{l}1278.08(5+) \\
1596.77(4+)\end{array}$ & $\mathrm{X}$ & $\sqrt{ }$ & $\checkmark$ & 6384.21 & 6383.68 & 6 & 5 & 3 & 1 & \\
\hline $\begin{array}{l}1639.2(4+) \\
2185.8(3+)\end{array}$ & $x$ & $\checkmark$ & Q & 6533.43 & 6554.78 & 4 & 6 & 5 & 1 & \\
\hline $\begin{array}{l}1318.43(5+) \\
1648.68(4+)\end{array}$ & $\sqrt{ }$ & $\sqrt{ }$ & $\sqrt{ }$ & 6588.91 & 6586.78 & 6 & 6 & 3 & 1 & \\
\hline
\end{tabular}

alons refer to the $\mathrm{m} / \mathrm{z}$ and charge (in parentheses) of detected species derived from Figures $6 \mathrm{c}+\mathrm{f}$.

bPrecursor ion scans are at the $\mathrm{m} / \mathrm{z}$ indicated: $\mathrm{m} / \mathrm{z} 2219$ for the presence of bisecting GlcNAc, $\mathrm{m} / \mathrm{z} 2280$ for the absence of bisecting GlcNAc, and relate data from Figures $8 \mathrm{a}+\mathrm{b}$. The scan at $m / z 512$ is for the presence of Lewis $X$, as shown in Figure 9.

${ }^{c} \sqrt{ }$ Indicates presence of an ion. or

dX Absence of an ion in the respective scan.

${ }^{\mathrm{e}} \mathrm{Q}$ Indicates that CAD on a $\mathrm{Q}-\mathrm{TOF}$ instrument was required for full characterization of a given feature.

${ }^{\mathrm{f}}$ The discrepancy in mass shown here is discussed in the text.

${ }^{g}$ Composition relates to the composition of the glycan moiety based on measured mass.

h $\mathrm{Structure}$ is the structure of the glycan moiety concluded from the precursor ion scans.

eties, resolution could not be achieved by this method alone, but an additional precursor ion scan for sialic acid can resolve these problems. Although sialic acid often gives intense $\mathbf{B}$ ions $(\mathrm{m} / \mathrm{z}=274 / 292)$ from product ion scanning, attempts to precursor ion scan at $m / z 274$ resulted in poorly resolved spectra (not shown). This is not due to the nature of the scan itself, since a similar scan on the fetuin glycopeptides produced similar results to the $\mathrm{m} / \mathrm{z} 204 \mathrm{scan}$. It may be, in part, due to the heterogeneity of the sialylated species present and the low amounts of sample, bringing the signal below the detection limit.

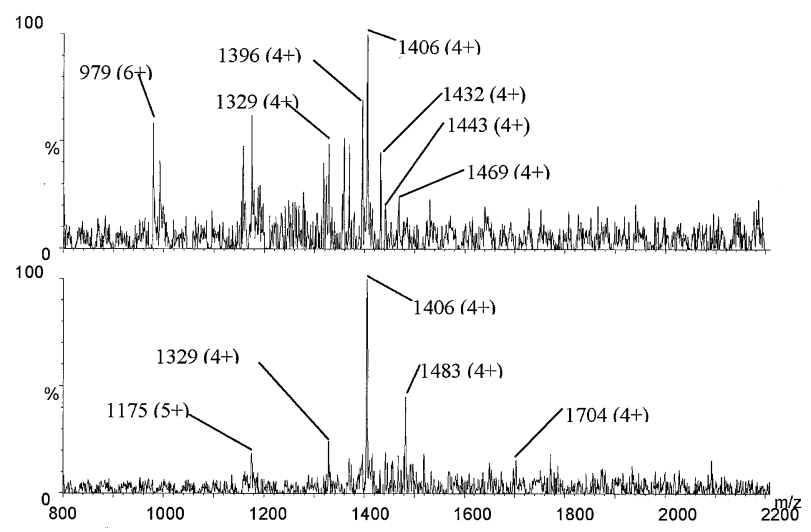

Figure 8. Structural precursor ion scans on the Asn 181 glycosylation site of the prion protein. (a) Scan at $m / z 2280$ for the $4_{\alpha^{\prime}} 4_{\beta}$ fragment ion $\left(2+\right.$ ion for peptide $\left.+\mathrm{Hex}_{3} \mathrm{HexNAc}_{2}\right)$ indicative of the absence of bisecting GlcNAc. (b) Scan at $m / z 2219$ for the $3_{\alpha}, 3_{\beta}$ fragment ion $\left(2+\right.$ ion for peptide $\left.+\mathrm{HexHexNAc}_{3}\right)$, indicative of the presence of GlcNAc $\beta$ 1-4 to the core mannose (bisecting GlcNAc).
Once data from each of the precursor ion scans have been analyzed and collated, it can be trivial to determine the structures of the saccharides. For example, from the $Y_{1}$ precursor ion scan a glycopeptide of mass 5766.6 Da could be detected. Subtraction of the mass of the peptide leaves a mass of 2101.5 $\mathrm{Da}$ for the carbohydrate implying a composition of $\mathrm{Hex}_{4} \mathrm{HexNAc}_{5} \mathrm{Fuc}_{3}$. The $4+$ ion of this glycopeptide $(\mathrm{m} / \mathrm{z} 1442.8)$ appears in the precursor ion scan for the absence of bisecting GlcNAc, but not in the precursor ion scan for the presence of this motif, implying a single structural isomer without bisecting GlcNAc. Having determined the saccharide core, this leaves three HexNAc moeities (hence tri-antennary), two fucoses, and an additional hexose. The $5+$ ion of this glycopeptide $(\mathrm{m} / \mathrm{z}$ 1154.2) appears in the Lewis $\mathrm{X}$ scan and from this information the outer arm structures may all be defined.

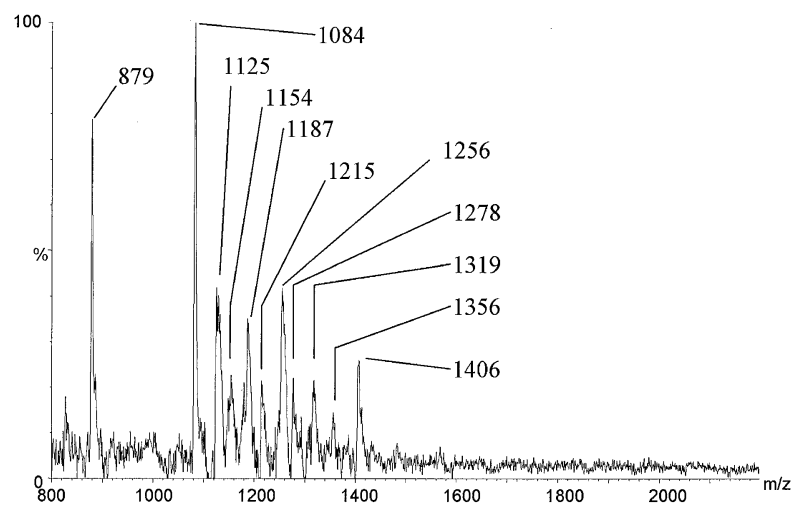

Figure 9. Precursor ion scan at $m / z 512$ for $\mathrm{PrP}^{\mathrm{Sc}}$ glycopeptide structures from the Asn 181 site carrying the Lewis X epitope. 
In some cases, however, structures are more problematic; structural scans need to be analyzed more closely and structures can be extrapolated from knowledge of glycobiology. For example, in the case of the glycopeptide of measured mass $6076.14 \mathrm{Da}$, three possible structures were considered: One afucosyl and disialylated, one difucosylated and monosialylated, and one asialyl with tetrafucosylation (i.e., three outer arms fucoses). Precursor ion ruled out both the afucosyl (as Lewis $X$ was present) and tetrafucosylated structure (as with a bisecting GlcNAc the structure would be biantennary, hence unable to support that degree of fucosylation).

The $m / z 2219$ and 2280 scans for presence or absence of bisecting GlcNAc may also help to resolve unrelated structures that are close in mass. For instance, the ion with $\mathrm{m} / \mathrm{z} 1175$ ion appears in both the $\mathrm{m} / \mathrm{z} 2219$ and the 2280 scans, implying two structures, one with a bisecting GlcNAc and the other without. The measured mass indicates a digalactosylated bianntennary, with no spare HexNAc moieties for a bisecting GlcNAc (hence a non-bisecting structure). The only other possible structure that could have bisecting GlcNAc is the glycopeptide corresponding to an ion at $\mathrm{m} / \mathrm{z} 1174.23$, an agalactosyl tetraantennary. These ions are not resolvable by this instrument under these conditions, but can be resolved by the structural precursor ion scans.

The carbohydrate structures deduced from this work are shown in Table 3. Product ion scans were used to determine the presence or absence of NeuAc when the possibility of sialylation required further investigation. In the case of particularly weak ions, undetected by the structural precursor ion scans, product ion scans were done by use of a Q-ToF instrument. In rare cases (glycopeptides of mass 5912.2 and $5785.1 \mathrm{Da}$ ) product ion scanning was required to accurately characterize the structure of the glycopeptide. Many confirmatory product ion scans were also conducted on established structures. Saccharides are presented as determined core structures, with determined outer arm structures. Where only one possibility of outer arm connectivity exists, structures are shown without ambiguity. The inclusion of brackets (Table 3 ) is to indicate that linkage information has not been generated and thus outer arm structures could have various different linkages. Although linkage information is required to completely characterize the structures of individual carbohydrates, relatively few techniques exist that can reliably provide this information. The elucidation of core and outer arm structures, as well as the presence/absence of bisecting GlcNAc moieties, however, represents a major advance from carbohydrate compositional information.

Structures detected and characterized encompass a range of structures from bisected monoantennaries up to non-bisected pentaantennaries, almost all fucosylated and a significant proportion carrying the Lewis $\mathrm{X}$ epitope. Sialylation is also common but not widespread. Out of the 35 structures identified, around half have been previously characterized in hamster 263k scrapie. The proposed gly-
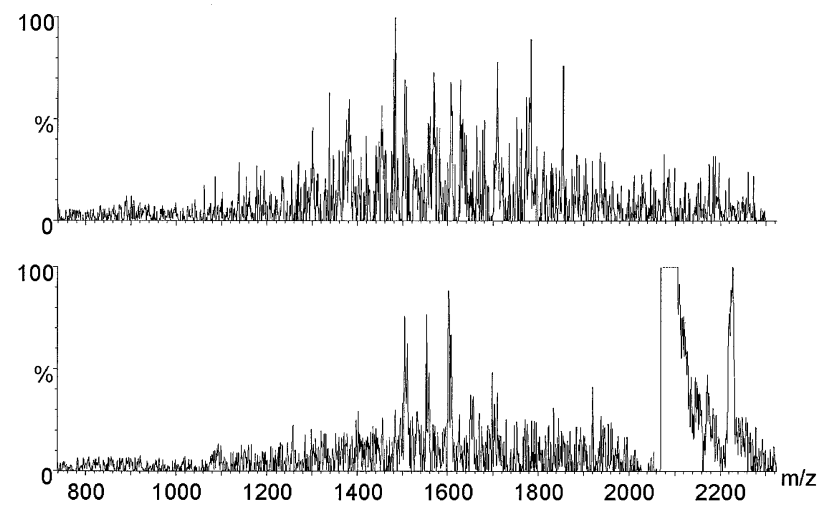

Figure 10. Preliminary precursor ion scans for Asn 197 site glycopeptides. (a) Scan at $m / z 1357$ for $Y_{1 \alpha} Y_{1 \beta}$ fragment ion, 1152 Da peptide + HexNAc. (b) Scan at $m / z 2074$ for the $Y_{3 \alpha}, Y_{3 \beta}$ fragment ion indicating the presence of a bisecting GlcNAc.

copeptides are often structural isomers of previously identified glycans, low in abundance, and usually detected as a consequence of bisect/non-bisect precursor ion scanning. This may be as a product of a small amount of bisected glycans forming the $4_{\alpha}, 4_{\beta}, 3_{\gamma}$ fragment ion, which had not been previously observed in product ion scans. Alternatively these may have been minor components that were not detected in other MS studies, which were not designed to detect structural isomerism.

\section{Asn 197 Site}

PNG'ase removal of the glycan chain revealed heterogeneity in the glycosylated peptide. As noted in earlier work [14], cleavage at Lys 194 can be variable, and the Nterminal glutamine of uncleaved peptide is partly converted to pyro-glutamic acid, resulting in a variety of different size peptides containing this glycosylation site. This heterogeneity, in addition to that of the carbohydrates themselves, makes analysis more complex. Only preliminary data has been acquired, but the glycosylation on each of the three peptides can be evaluated independently using three different sets of precursor ion scans. The glycosylation at this site has been shown to be the most heterogeneous of the two sites [14] and the increased variety in glycan structures at this site is immediately obvious from the $Y_{1}$ precursor ion scan for the shortest of the three peptides (Figure 10a). Putative compositions can be determined based on this data, and structures can be tentatively assigned from the accompanying bisect ion scan (Figure 10b), however no assignments are given here. Full characterization of this site will appear in a later publication.

\section{Conclusion}

In this paper we report a rapid and sensitive method for glycopeptide detection and characterization. Changes in glycoform pattern can quickly and easily be determined, and fine characterization can be done at a later stage if desired, by complementary methods including exoglycosidase digestion and product ion scanning. This 
method requires minimum handling past protein purification, so can bypass the need for HPLC purification of protein digests whilst still giving site specific information. No derivatization or labeling is required. With an array of complex glycans, structural data can be obtained for the pool by precursor ion scanning for fragmentation ions indicative of certain characteristics. Once glycoform patterns have been established only a rapid glycopeptide based $Y_{1}$ precursor ion scan need be applied to an unseparated protein digest to obtain a glycoform profile.

\section{Acknowledgments}

This work was funded on a BSEP phase IV grant from the BBSRC. The authors would like to thank Dr. James Hope for his contribution to this project, and also Dr. Pauline Rudd, Dr. David Harvey, and Professor Raymond Dwek of the Glycobiology Institute, Oxford, UK for their assistance and guidance. They also thank the PrP Structure and Function group at IAH, Compton and Lawrence Hunt for constructive comments.

\section{References}

1. Helenius, A.; Aebi, M. Intracellular Functions of N-Linked Glycans. Science 2001, 291, 2364-2369.

2. Dwek, R. A. Glycobiology: Toward Understanding the Function of Sugars. Chem. Rev. 1996, 96, 683-720.

3. Rudd, P. M.; Elliott, T.; Cresswell, P.; Wilson, I. A.; Dwek, R. A. Glycosylation and the Immune System. Science 2001, 291, 2370-2376.

4. Parekh, R. B.; Dwek, R. A.; Sutton, B. J.; Fernandes, D. L.; Leung, A.; Stanworth, D.; Rademacher, T. W. Association of Rhuematoid Arthritis and Primary Osteoarthritis with Changes in the Glycosylation Pattern of Total Serum IgG. Nature 1985, 316, 452-457.

5. Parekh, R.; Isenberg, D.; Rook, G.; Roitt, A. Comparative Analysis of Disease-Associated Changes in the Galactosylation of Serum IgG. J. Autoimmun. 1989, 2, 101-114.

6. Turner, G. Haptoglobin-A Potential Reporter Molecule for Glycosylation Changes in Disease. Adv. Exp. Med. Biol. 1995, 376, 231-238.

7. Maguire, T.; Breen, K. A Decrease in Neural Sialyltransferase Activity in Alzheimers Disease. Dementia 1995, 6, 185-90.

8. Maguire, T.; Thakore, J.; Dinan, T. G.; Hopwood, S.; Breen, K. C. Plasma Sialyltransferase Levels in Psychiatric Disorders as a Possible Indicator of HPA Axis Function. Biol. Psychiat. 1997, 41, 1131-1136.

9. Mackiewicz, A.; Dewey, M. J.; Berger, F. G.; Baumann, H. Acute Phase Mediated Change in Glycosylation of Rat Alpha 1-Acid Glycoprotein in Transgenic Mice. Glycobiol. 1991, 1, 265-269.

10. Medzihradszky, K. F.; Maltby, D. A.; Hall, S. C.; Settineri, C. A.; Burlingame, A. L. Characterization of Protein N-Glycosylation by Reversed-Phase Microbore Liquid Chromatography/Electrospray Mass Spectrometry, Complementary Mobile Phases, and Sequential Exoglycosidase Digestion. Am. Soc. Mass Spectrom. 1994, 5, 350-358.

11. Wilm, M.; Neubauer, G.; Mann, M. Parent Ion Scans of Unsepparated Peptide Mixtures. Anal. Chem. 1996, 68, 527-533.

12. Huddleston, M. J.; Bean, M. F.; Carr, S. A. Collisional Fragmentation of Glycopeptides by Electrospray Ionization LC MS and LC MS MS-Methods for Selective Detection of Glycopeptides in Protein Digests. Anal. Chem. 1993, 65, 877-884.

13. Gerwig, G.; Vliegenthart, J. Analysis of Glycoprotein-Derived Glycopeptides. EXS 2000, 88, 159-186.

14. Stimson, E.; Hope, J.; Chong, A; Burlingame, A.L. Site-specific characterization of the N-linked glycans of murine prion protein by high-performance liquid chromatography/electro- spray mass spectrometry and exoglycosidase digestions. Biochem. 1999, 38, 4885-4895.

15. Rudd, P. M.; Endo, T.; Colominas, C.; Groth, D.; Wheeler, S. F.; Harvey, D. J.; Wormwald, M. R.; Serban, H.; Prusiner, S. B.; Kobata, A.; Dwek, R. A. Glycosylation Differences Between the Normal and Pathogenic Prion Isoforms. PNAS U.S.A. 1999, 96, 13044-13049.

16. Hope, J.; Multhaup, G.; Reekie, L. J.; Kimberlin, R. H.; Beyreuther, K. Molecular Pathology of Scrapie-Associated Fibril Protein (PrP) in Mouse Brain Affected by the ME7 Strain of Scrapie. Eur. J. Biochem. 1988, 172, 271-277.

17. Annan, R. S.; Carr, S. A. The Essential Role of Mass Spectrometry in Characterizing Protein Structure: Mapping Posttranslational Modifications. J. Protein Chem. 1997, 16, 391-402.

18. Domon, B.; Costello, C.E. A Sytematic Nomenclature for Carbohydrate Fragmentations in FAB/MS Spectra of Glycocojugates. Glycoconj. 1988, 5, 397-409.

19. Green, E. D.; Adelt, G.; Baenziger, J. U.; Wilson, S.; Van Halbeek, H. The Asparagine Linked Oligosaccharides on Bovine Fetuin. J. Biol. Chem. 1988, 263, 18253-18268.

20. Rice, K. G.; Rao, N. B. N.; Lee, Y. C. Large Scale Preparation and Characterization of N-Linked Glycopeptides from Bovine Fetuin. Anal. Biochem. 1990, 184, 249-258.

21. Stahl, N.; Baldwin, M. A.; Hecker, R.; Pan, K. M.; Burlingame, A. L.; Prusiner, S. B. Glycosylinositol Phospholipid Anchors of the Scrapie and Cellular Prion Proteins Contain Sialic-Acid. Biochem. 1992, 31, 5043-5053.

22. Turk, E.; Teplow, D. B.; Hood, L. E.; Prusiner, S. B. Purification and Properties of the Cellular and Scrapie Hamster Prion Proteins. Eur. J. Biochem. 1988, 176, 21-30.

23. Gill, A. C.; Ritchie, M. A.; Hunt, L. G.; Steane, S. E.; Davis, K. G.; Bocking, S. P.; Rhie, A. G. O.; Bennett, A. D.; Hope, J. Post-Translational Hydroxylation at the N-Terminus of the Prion Protein Reveals the Presence of PPII Structure in Vivo. EMBO J. 2000, 19, 5324-5331.

24. Lehmann, S.; Harris, D. A. Blockade of Glycosylation Promotes Acquisition of Scrapie-Like Properties by the Prion Protein in Cultured Cells. J. Biol. Chem. (1997, 272, 21479-21487)

25. Hope, J.; Wood, S.; Birkett, C.; Chong, A.; Bruce, M.; Cairns, D.; Goldmann, W.; Hunter, M.; Bostock, C. Molecular Analysis of Ovine Prion Protein Identifies Similarties Between BSE and an Experimental Isolate of Natural Scrapie, CH1641. J. Gen. Virol. 1999, 80, 1-4.

26. Priola, S. A.; Lawson, V. A. Glycosylation Influences CrossSpecies Formation of Protease-Resistant Prion Protein. EMBO 2001, 20, 3392-6699.

27. Somerville, R. A. Host and Transmissible Spongiform Encephalopathy Agent Strain Control Glycosylation of PrP. J. Gen. Virol. 1999, 80, 1865-1872.

28. Stahl, N.; Baldwin, M. A.; Teplow, D.; Hood, L.; Beavis, R.; Chait, B.; Gibson, B. W.; Burlingame, A. L.; Prusiner, S. B. Prion Diseases of Humans and Animals. Ellis Horwood Ltd: Chichester, UK, 1992; pp. 361-379.

29. Chen, Y. J.; Wing, D. R.; Guile, G. R.; Dwek, R. A.; Harvey, D. J.; Zamze, S. Nuetral N-Glycans in Adult Rat Brain Tissue. Eur. J. Biochem. 1997, 251, 691-703.

30. Zamze, S.; Harvey, D. J.; Chen, Y. J.; Guile, G. R.; Dwek, R. A.; Wing, D. R. Sialylated N-Glycans in Adult Rat Brain Tissue-a Widespread Distribution of Disialylated Antennae in Complex and Hybrid Structures. Eur. J. Biochem. 1998, 258, 243-270.

31. Harvey, D. J. Electrospray Mass Spectrometry and Fragmentation of N-linked Carbohydrates Derivatized at the Reducing Terminus. J. Am. Soc. Mass Spectrom. 2000, 11, 900-915.

32. Spina, E.; Cozzolino, R.; Ryan, E.; Garozzo, D. Sequencing of Oligosaccharides by Collision Induced Dissociation Matrix Assisted Laser Desorption/Ionization Mass Spectrometry. J. Mass. Spectrom. 2000, 35, 1042-1048. 